\title{
Field Experiments with a Grooming Switch for OTDM Meshed Networking
}

\author{
G. Zarris, E. Hugues-Salas, N. Amaya Gonzalez, R. Weerasuriya, F. Parmigiani, D. Hillerkuss, P. \\ Vorreau, M. Spyropoulou, S. K. Ibrahim, A. D. Ellis, R. Morais, P. Monteiro, P. Petropoulos, D. J. \\ Richardson, I. Tomkos, J. Leuthold, and D. Simeonidou
}

\begin{abstract}
Field experiments of 42.7 / $128.1 \mathrm{~Gb} / \mathrm{s}$ WDM-OTDM transmultiplexing and all-optical dual-wavelength regeneration at the OTDM rate are presented. By using the asynchronous retiming scheme, we achieve error-free buffer-less data grooming with time-slot interchange (TSI) capability for OTDM meshed networking. We demonstrate excellent performance from the system, discuss scalability, applicability, and the potential reach of the asynchronous retiming scheme for transparent OTDMdomain interconnection.
\end{abstract}

Index Terms-Optical communication, synchronization, optical signal processing, time division multiplexing, ultrafast optics.

\section{INTRODUCTION}

A LARGE research effort is being directed in recent years in enabling $100 \mathrm{Gbit} / \mathrm{s}$ Ethernet (100GE) transmission on a single channel over long and ultra-long haul (ULH) distances, and within the existing fibre plant and WDM infrastructure. This challenge is being dealt with quite successfully with the introduction of multi-level single-carrier [1], [2] and multi-carrier [3], [4] modulation formats, and associated hardware implementations for data generation, detection and error correction. Many of the transmission

Manuscript received May 31, 2009. This work was supported in part by the by the European projects TRIUMPH (grant IST-027638 STP) and Euro-Fos (NoE 224402), and in part by the UK's Education and Research Network (JANET), and the Science Foundation Ireland (grant 06/IN/I969).

G. Zarris, E. Hugues-Salas, N. Amaya Gonzalez, and D. Simeonidou are with the Photonic Networks Laboratory, University of Essex, Colchester CO4 3SQ, U.K., (phone: +44-1206-874257; e-mail: gzarris@essex.ac.uk).

R. Weerasuriya, S. K. Ibrahim, and A. D. Ellis are with the Tyndall National Institute and Department of Physics, University College Cork, Ireland (phone: +353-21-490-4858; fax: +353-21-490-4880; e-mail: andrew.ellis@tyndall.ie).

F. Parmigiani, P. Petropoulos, and D. J. Richardson are with the Optoelectronics Research Centre, University of Southampton, Southampton SO17 1BJ, U.K., (phone: +44 238059 3172; email: frp@orc.soton.ac.uk).

D. Hillerkuss, P. Vorreau, and J. Leuthold are with the Institute of Photonics and Quantum Electronics, University of Karlsruhe, 76131 Karlsruhe, Germany, (phone: +49 (721) 608-7173; email: p.vorreau@,ihq.unikarlsruhe.de).

M. Spyropoulou, and I. Tomkos are with Athens Information Technology Centre, Athens, Greece, (phone: +30 (210) 668-2778; email: mspi@ait.edu.gr).

R. Morais, and P. Monteiro are with Nokia Siemens Networks Portugal S.A., Rua Irmãos Siemens 1, Alfragide 2720-093 Amadora, Portugal, (phone: 00351214242561; email: rui.morais@nsn.com). techniques that are being developed in optical research labs worldwide are based on concepts that have long been implemented and matured in the electronic and wireless communications. In many cases the application of such communications concepts in optics has been made possible by the continuous advancement in computational speed of digital electronics. Nevertheless, electronics do not scale well in terms of transmission in RF lines and clock speed [5], which leads to the problem of finding efficient and 'future-proof' (i.e. bit-rate-scalable) ways for generating, detecting, grooming, and switching 100's Gb/s (or higher) single channel speeds, that are anticipated in the future network.

In addition, it has been reasoned that, as network traffic rates increase, the significance of data traffic grooming will increase, not least because of its current predominately electronic nature and, therefore, limited scalability in terms of cost and power consumption [6]. It is possible that the significance of data grooming may be currently masked by the proliferation of optical and electronic by-pass [7], which gradually increases the efficient use of resource-consuming fine-granularity packet routers. When these efficiency gains take hold, data grooming may once again become top research priority. Furthermore, studies show [8] that, as network access data rates increase, aggregated data rates need to increase in proportion to the access speeds in order to maintain the efficient use of network resources. Therefore, future high capacity networks may require a coarse granularity of 100's $\mathrm{Gb} / \mathrm{s}$, or more.

In this context, optical time-division multiplexing (OTDM) [9], which capitalizes on the inherent high-speed characteristic of optical devices, may find increasing relevance, because OTDM channels can be made to have the capacity of the desirable coarse-granularity channel; and when a coarse channel is routed in the network only one physical channel needs to be switched. Multi-Tb/s OTDM generation / demultiplexing [10], and transmission [11], [12] has been reported, and the highest single channel capacities involve multi-level modulation formats for the OTDM channel tributaries, together with polarization multiplexing. This has the advantage of requiring a lower pulse rate (Baud rate), which reduces the stringent requirements in pulse generation and time alignment, transmission, demultiplexing, and clock recovery. 

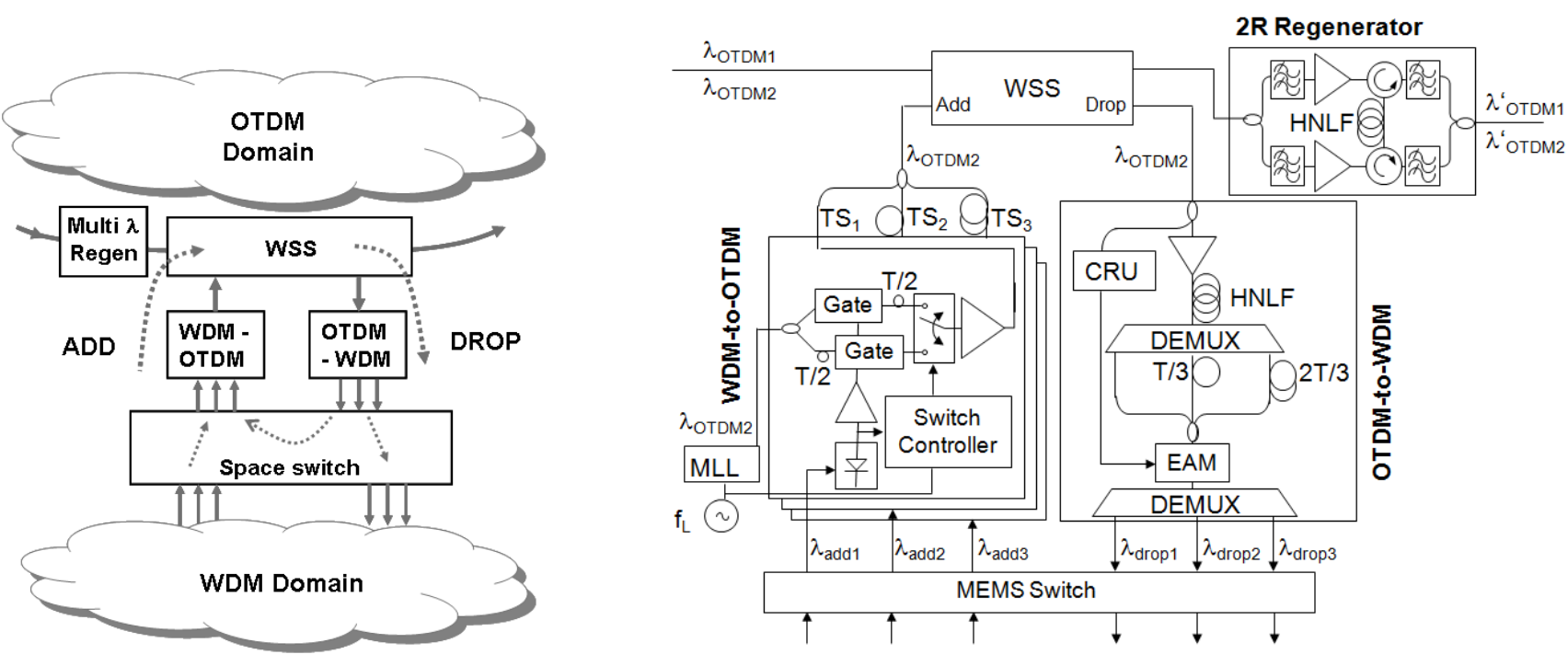

Fig. 1. a) Block diagram of the switch architecture; b) Grooming switch implementation [21]

To realize the potential benefits of OTDM in a multigranular network, techniques and technologies for the realization of time-domain routing (i.e. routing of OTDM time-slots) will be necessary [13]. In particular, time-domain optical add-drop multiplexers (TD-OADM) [14], [15] would be key network elements in OTDM ring architectures; whereas time-domain optical cross-connects, with time-slot interchange (TSI) functionality [16] would be necessary for mesh connectivity. However, in order to perform time-domain routing, retiming of tributaries is necessary. This involves both synchronizing the tributary data rates - since data rates are different for tributaries that are generated at different, remote locations - and phase aligning the pulses. An effective solution to this problem had not been reported until very recently [17] when the asynchronous digital optical regeneration (ADORE) concept [18], [19] was applied to OTDM/WDM networks (i.e. with the retiming applied at tributary level). For example, previously, in [14] delay lines were considered, but these have to offer impractically long delays; and in [20] synchronism between WDM channels, before the OTDM grooming takes place, was attained by imposing severe restrictions in terms of networking, choice of wavelengths, and reach.

From this perspective and to our knowledge, in this paper we report on the first experiments in deployed fiber of a novel $42.7 / 128.1 \mathrm{~Gb} / \mathrm{s}$ grooming switch [21], [22] which provides the necessary functionality for OTDM meshed networking. In particular, we demonstrate in the field, first, transparent WDM-to-OTDM data grooming (with TSI functionality), without using buffers, by applying the ADORE concept for bit-wise tributary synchronisation; second, simultaneous OTDM demultiplexing of all tributaries; and third, all-optical dual-wavelength regeneration at the OTDM bit-rate.

The rest of the paper is organised as follows: In section II we describe the grooming switch design. In section III we describe the network concept on which two experiments were based, and we discuss the potential of asynchronous retiming concept in terms of reach. In section IV we present the experimental setup and results from the two experiments which were designed to demonstrate the functionality and performance of the switching node within the network concept presented in section III. Finally, section V summarizes our findings and discusses scalability, and the limitations and applicability of our approach.

\section{SWITCHING NODE ARCHITECTURE AND IMPLEMENTATION}

Fig. 1a is a block diagram of the switch architecture. Upon entering the node the OTDM channels are first 2R regenerated in the multi-wavelength regenerator and then enter $\mathrm{a}$ wavelength selective switch (WSS). Depending on its wavelength, an OTDM channel is either dropped or passed through the node. A dropped OTDM channel is timedemultiplexed in the OTDM-to-WDM unit into its tributaries, with each tributary being mapped onto a selectable wavelength channel. It should be noted that although only one such unit is shown, a number of demultiplexing units may exist, each one processing one OTDM channel. All OTDM tributaries enter a space switch, typically based on microelectromechanical systems (MEMS) switch fabric. There are two possibilities for each tributary: First, the tributary is switched to a lower bit-rate domain, denoted as 'WDM domain'; and second, a tributary is looped-back and enters a WDM-to-OTDM subsystem. This subsystem combines lower bit-rate channels - switched from either the WDM domain or looped-back from the OTDM-to-WDM subsystem - and maps them onto OTDM tributaries to form a new higher bit-rate OTDM channel, which subsequently enters the OTDM domain. As it will become apparent, the port scalability of this architecture, in terms of both OTDM and WDM channels, is restricted only by the dimension of the space switch. 
Fig. 1b depicts our implementation of the grooming switch, reported in [21], which provides the transmultiplexing functionality and signal regeneration outlined in Fig. 1a. (Note that the regenerator can be placed at either input or output of the node). The current implementation of this switch is capable of performing OTDM-to-WDM and WDM-to-OTDM conversions between one $128.1 \mathrm{~Gb} / \mathrm{s}(3 \times 42.7 \mathrm{~Gb} / \mathrm{s})$ higher bit-rate OTDM channel and three $42.7 \mathrm{~Gb} / \mathrm{s}$ lower bit-rate WDM channels; while the $2 \mathrm{R}$ regenerator is capable of regenerating up to two OTDM channels, $\lambda_{\text {OTDM1 } 1}, \lambda_{\text {OTDM2 }}$, and is henceforth referred to as dual-wavelength regenerator. The WSS is implemented with a set of two tunable $5 \mathrm{~nm}$ full-width half-maximum (FWHM) band-pass filters. The space switch is based on a $8 \times 8$ dimension MEMS switch fabric, with reconfiguration time of the order of $1 \mathrm{~ms}$. All $42.7 \mathrm{~Gb} / \mathrm{s}$ channels, whether originating in the OTDM domain or the WDM domain, are input to the MEMS space switch, which provides non-blocking circuit connectivity. With reference to Fig. 1b, we will now describe the three main building blocks of the grooming switch: WDM-to-OTDM, OTDM-to-WDM, and $2 \mathrm{R}$ regenerator.

\section{A. WDM-to-OTDM subsystem}

The WDM-to-OTDM consists of three ADORE units, each mapping one $42.7 \mathrm{~Gb} / \mathrm{s}$ on/off keying (OOK) channel on one of the three OTDM time-slots, TS1, TS2, TS3. It can be seen that each ADORE addresses a certain time-slot. Therefore, by re-arranging the connectivity of $\lambda_{\text {add1 }}, \lambda_{\text {add2 }}, \lambda_{\text {add } 3}$ with the MEMS switch, TSI operation can be performed.

Any process of WDM-to-OTDM mapping should involve the following: (i) narrowing of the lower bit-rate time-slot in order to fit the OTDM time-slot; (ii) converting the lower bitrate wavelengths into a common wavelength; (iii) retiming these lower bit-rates [17]. The retiming function concerns the translation of the input signal frequency (or bit-rate), $f_{D}$, to a frequency determined by a shared node-specific local clock, $\mathrm{f}_{\mathrm{L}}$. With the dual-gate ADORE (as shown in Fig. 1b), retiming is attained by taking one sample of the data waveform every $\mathrm{T} / 2$ (where $\mathrm{T}$ is the lower rate bit-slot duration) with a modelocked laser (MLL) locked at the local frequency, $f_{L}$. Each of the two samples within a bit-slot propagates in a different light-path, and the path which most faithfully reproduces the input data is switched to the output, using a cross-bar switch. In our implementation, the 'switch controller' includes a phase comparator, which compares the input data phase with the phase of the local clock. The pulse width and wavelength of all OTDM tributaries derive from the MLL, and since this is common within one WDM-to-OTDM subsystem (here, $\left.\lambda_{\text {OTDM2}}\right)$, all tributaries have the same pulse width and wavelength. It should be noted that the cross-bar switch only switches between paths when the input data phase changes appreciably, which happens in timescales much longer than 1 $\mathrm{ms}$, as we will see in section III.B. Upon switching bit-slot slippage (by one bit-slot) may occur. In addition, during switching data may be lost, depending on how fast the rise and fall time of the switch is. It is therefore necessary to provide a mechanism for maintaining data integrity. A simple mechanism is provided in the form of guard-band between data blocks as in [19] (see also section III.B.). Accordingly, the switch controller in Fig. $1 \mathrm{~b}$ also takes into account whether a guard-band is present, and is only allowed to change the state of the cross-bar switch during a guard-band.

It should be noted that Fig. 1b depicts the principle of operation of the dual-gate ADORE. A more accurate representation of the ADORE architecture used in the experiments of section IV is shown in Fig. 2. This is the dualgate single Mach-Zehnder modulator (MZM) ADORE, as reported in [23], [24], apart from the pulsed source which is now replaced by a fiber-based $40 \mathrm{GHz}$ hybridly-mode-locked MLL. In this configuration the detected data is first reshaped (specifically, converted to non-return-to-zero, NRZ, format) and then input to a driver amplifier which drives one $40 \mathrm{~Gb} / \mathrm{s}$ Lithium-Niobate (LN) MZM. The MZM samples one of two trains of clock pulses, having $\mathrm{T} / 2$ phase difference, and both generated from the MLL driven by the local clock. A phase comparator (including a $40 \mathrm{GHz}$ RF mixer) within the switch controller determines the optimum switch state of the $2 \times 1$ optical switch. A separate input to the said controller (not shown in Fig. 2) is provided by a $100 \mathrm{MHz}$ photodiode (PD) which detects the power envelope of the input data signal, in order to detect the presence of guard-band (see section IV.B). Based on these two conditions, i.e. optimum switch state and guard-band presence, the $2 \times 1$ optical switch, with $440 \mathrm{~ns}$ switching time, switches-in the optimum path. The signal at the output of the switch will have the same characteristics with the local optical clock in terms of pulse width and wavelength. It will also be aligned to a fixed output phase, independent of the incoming data phase, and irrespectively of the path the MLL pulses pass through. It should be noted that the two tunable delays in Fig. 2 are only required in a prototype subsystem, and are adjusted at the beginning of each experiment to account for thermal drifts in the light-paths.

In order to save on the required hardware in our implementation, the WDM-to-OTDM consisted of one dualgate single MZM ADORE and two reduced versions of an

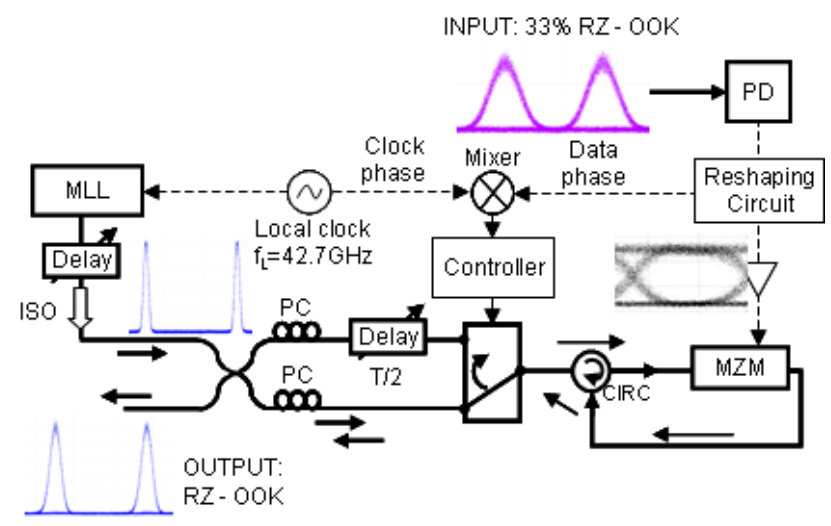

Fig. 2. The dual-gate single MZM ADORE used in the experiments [23]. Dashed lines: RF lines. Solid lines: Optical paths. ISO: Isolator, CIRC: Circulator, PD: $40 \mathrm{GHz}$ Photodiode, MZM: $\mathrm{LiNbO}_{3}$ Mach-Zehnder modulator, PC: Polarization controller, MLL: Mode-locked laser 
ADORE, offering very similar performance but without automatic phase selection functionality [25]. Therefore, in the experiments that follow, full retiming was only performed on one input tributary, and the other two tributaries were synchronous with the frequency of the MLL, and at their respective optimum input phases. Nevertheless, we can still draw the same conclusions as if we had three ADORE units, since we have confirmed experimentally [25] that when a number of ADORE units are employed in parallel, they may be considered independently, with negligible penalty associated with phase tuning of adjacent channels.

\section{B. OTDM-to-WDM}

In this subsystem the OTDM signal is first amplified and then its spectrum is broadened by self-phase modulation (SPM) in a $310 \mathrm{~m}$-long highly non-linear fiber (HNLF) with chromatic dispersion of $-0.31 \mathrm{ps} / \mathrm{nm} / \mathrm{km}$, dispersion slope of $0.0031 \mathrm{ps} / \mathrm{nm}^{2} / \mathrm{km}$, nonlinear coefficient of $22(\mathrm{Wkm})-1$, and attenuation of $1.21 \mathrm{~dB} / \mathrm{km}$ (all data are specified at $1550 \mathrm{~nm}$ ). Next, the broadened spectrum is offset-filtered both sides of the spectrum (5 nm offset either side) with $2 \mathrm{~nm}$ FWHM band-pass filters (BPFs), yielding two replicas of the original 128.1 Gb/s data [26]. These two replicas plus the original signal (filtered with a $5 \mathrm{~nm} \mathrm{BPF}$ ) are delayed as shown (where $\mathrm{T} / 3$ is the bit-slot duration of the OTDM channel) and then are coupled together and enter an electro-absorption modulator (EAM) gate, driven by a sinusoidal signal at $42.7 \mathrm{GHz}$, which performs simultaneous demultiplexing by sampling a different OTDM tributary from each of the three replicas [27]. In this way, the three tributaries exit the subsystem at three different wavelengths: $\lambda_{\text {drop } 1}, \lambda_{\text {drop } 2}, \lambda_{\text {drop3 }}$. (A more detailed schematic of the subsystem is given in Fig. 6 in section IV.C, and also in [27]). The technique resembles those reported in [28], [29]. However, our implementation does not require a pulse source, it is simpler, it yields excellent performance, while it is still compatible with phase modulated formats.

The clock recovery unit (CRU), required for driving the EAM gate with a synchronous clock signal, is an optoelectronic oscillator as in [30], [31]. It oscillates at $42.7 \mathrm{GHz}$, and it includes a $40 \mathrm{GHz}$ EAM of low polarisation dependent loss (PDL), a $40 \mathrm{GHz}$ photodiode, a band-pass RF filter with resonant cavity of $\mathrm{Q}=1000$, and a manually adjustable variable optical delay line (VODL) for adjusting the loop length.

\section{C. $2 R$ dual-wavelength regenerator}

The $2 \mathrm{R}$ regenerator is also based on offset filtering of SPMbroadened spectrum in HNLF. The configuration, HNLF, and filters used were exactly as reported in [32]. This regenerator can simultaneously process two $128.1 \mathrm{Gbit} / \mathrm{s}$ channels, by launching them bi-directionally in the HNLF. In more detail, the two channels are launched into the regenerator, and are separated in two paths by 3nm FWHM BPFs. After amplification and further filtering with $5 \mathrm{~nm}$ FWHM BPFs, the two signals are fed into a single HNLF in opposite directions through optical circulators which route outgoing signals to the output of the regenerator. These outgoing signals are filtered with $2 \mathrm{~nm}$ FWHM BPFs at a blue offset of $2 \mathrm{~nm}$ with respect to the incoming wavelengths, yielding $\lambda^{\prime}$ OTDM1, and $\lambda^{\prime}$ OTDm2. The $348 \mathrm{~m}$-long HNLF used in this subsystem has a chromatic dispersion of $-0.8 \mathrm{ps} / \mathrm{nm} / \mathrm{km}$, a dispersion slope of $0.024 \mathrm{ps} / \mathrm{nm}^{2} / \mathrm{km}$, a nonlinear coefficient of $18 / \mathrm{W} / \mathrm{km}$, and an attenuation of $0.8 \mathrm{~dB} / \mathrm{km}$ (all data are specified at $1550 \mathrm{~nm})$. Note that the fiber properties were carefully selected following the design maps outlined in [33].

\section{NETWORK SCENARIO AND ASYNCHRONOUS RETIMING}

\section{A. Network scenario}

The network scenario we consider herewith takes into account the potential applicability of an OTDM meshed network-domain. OTDM transmission is faced with challenges, especially in terms of chromatic dispersion (CD) compensation, and polarization mode dispersion (PMD) mitigation [9]. Even with optical regeneration applied to the OTDM channels, transmission over certain long-haul routes may be unattainable due to, for example, poor performance or unsuitable design of the fiber plant, such as high PMD or inadequate optical signal-to-noise ratio (OSNR). In addition, as it was discussed in section I, the value of the OTDM approach would partly derive from its ability to carry the capacity of the coarse granularity in a multi-granular network.

The above arguments suggest that a potential applicability lies in the core or metro-core network, and over probably modest distances of up to a few hundred $\mathrm{km}$. One could envisage, therefore, OTDM islands (or domains) in the core network, interconnected with lower bit-rate, WDM links. Fig. 3 depicts a case within this framework, including the case of traffic grooming in an edge OTDM node.

In particular, the notation in Fig. 3 reflects the two experiments that were carried out in which one WDM channel, $\lambda_{1}$, from a remote site (through a fiber denoted as 'Ipswich') was combined with two local WDM channels to form an OTDM channel at $\lambda_{\text {OTDM2 }}$. This $\lambda_{\text {OTDM2 }}$ together with another $128.1 \mathrm{~Gb} / \mathrm{s}$ OTDM channel at $\lambda_{\text {OTDM1 }}$ (which transits Node 1) propagate in a fiber link ('Chelmsford') belonging to the OTDM domain and are input to Node 2. In Node 2 both signals are regenerated in the same dual-wavelength $2 \mathrm{R}$ regenerator and, subsequently, $\lambda_{\text {OTDM1 }}$ exits the node without further processing, and propagates in the same OTDM domain; while $\lambda_{\text {OTDM2 }}$ is dropped to the OTDM-to-WDM. All three tributaries of $\lambda_{\text {OTDM2 }}$ are now converted to the three WDM channels, $\lambda_{4}, \lambda_{5}, \lambda_{6}$, and are propagated in a WDM link ('Ipswich'), which 'bridges' two OTDM domains. These three WDM channels could be combined together in the WDM-toOTDM subsystem of Node 3 to form the same OTDM channel to be launched in the second OTDM domain. 


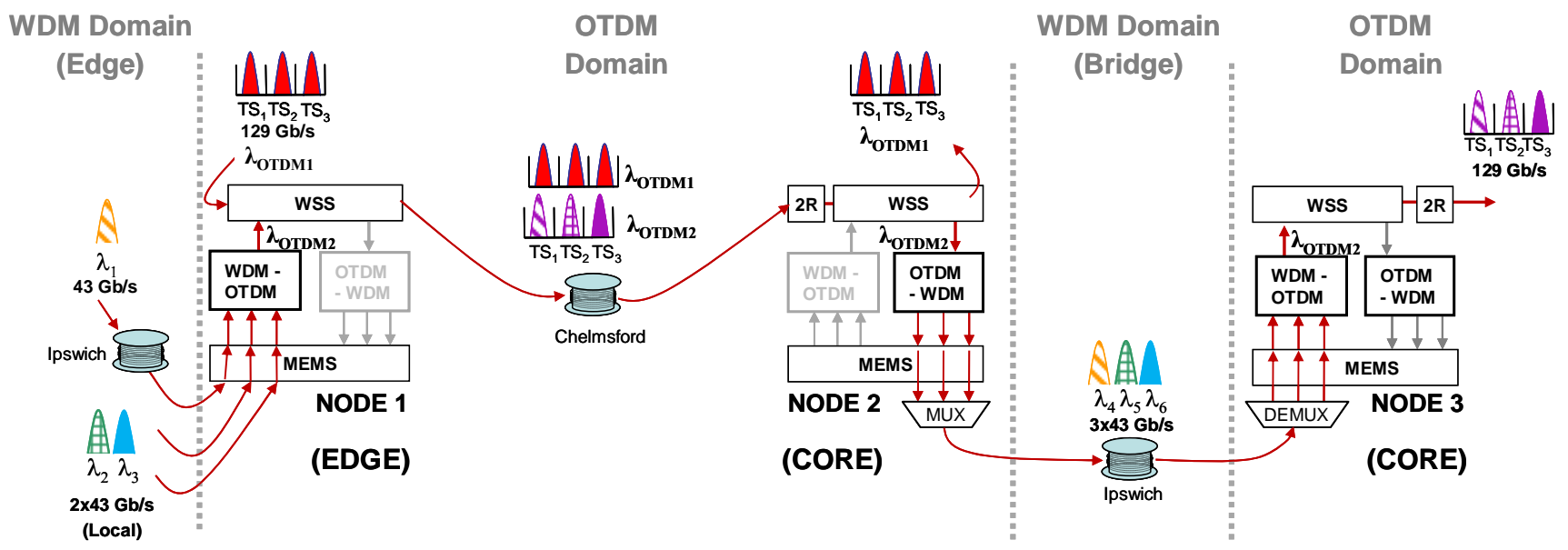

Fig. 3. The network scenario: Edge grooming, transmission, tributary separation, WDM bridge, and re-aggregation.

In the next section we will see that the above network scenario is demonstrated in two separate experiments, with the first experiment demonstrating the interoperability of Nodes 1 $\& 2$, and the second the interoperability of Nodes $2 \& 3$.

\section{B. Asynchronous retiming and network reach}

In the above scenario, it is of interest to consider the possible reach of the asynchronous retiming scheme, in order, for example, to be able to transparently interconnect (via ADORE units) two distant OTDM domains.

For the duration of a data block (i.e. between guard-bands) the ADORE cannot switch to an alternative sampling phase without loss of data (see section II.A). Therefore, for the duration of the data block, random changes in the data phase should not accumulate to more than a small fraction of the bitslot duration, T. In dispersion compensated links in which small wavelength drifts do not affect time-of-flight, there are two mechanisms which cause changes to the data phase: First, it is the clock accuracy, or frequency deviation between the local clock in the ADORE and the remote clock which produces the data. Secondly, it is the time-of-flight in the fiber, which - in the absence of residual dispersion - depends on its thermal expansion coefficient.

In terms of clock accuracy, technology advancements in chip-scale atomic clocks (CSAC) [34], with accuracies better than $10^{-11}$, makes possible the introduction of affordable, compact CSAC in metro-access and core network, alike. Therefore, if we consider 2 parts in $10^{11}$ relative drift in frequency between two clocks of $10^{-11}$ accuracy, $40 \mathrm{GHz}$ clock frequency, and $1 \mathrm{~ms}$ data block length, the expected maximum phase drift within a data block would be less than $10^{-3} \mathrm{~T}[18]$.

In terms of time-of-flight, if we consider a typical value for fiber thermal expansion of $10^{-6}$ [35] (which is equivalent to $0.5 \mathrm{~ns} / 100 \mathrm{~km} /{ }^{\circ} \mathrm{C}$ ), and $1{ }^{\circ} \mathrm{C}$ uniform change in temperature over 8 minutes over a ULH link, asynchronous retiming can exceed $100,000 \mathrm{~km}$ reach with $1 \mathrm{~ms}$ data block length, and at $40 \mathrm{~Gb} / \mathrm{s}$, assuming that the ADORE can tolerate $10^{-1} \mathrm{~T}$ phase drift within a data block.
It seems plausible, therefore, for the asynchronous retiming concept to extend over global distances. However, studies on the statistics of short term time-of-flight variations due to fiber expansion over ULH links would need to be done to confirm the above.

\section{FIELD EXPERIMENTS}

Two experiments were performed, first reported in [36], with the aim of demonstrating key network functions in the network scenario presented in section III.A (Fig. 3). All equipment resided in a lab environment in Colchester, apart from the dark fiber links and some of the Erbium-doped fiber amplifiers (EDFAs). We start with describing the dark fiber network used, before we present the experimental setup and results for each experiment.

\section{A. Dark fiber network}

The field experiments were performed using two dispersion compensated G.652 dark fibre sections between the towns of Ipswich, Colchester, and Chelmsford (Fig. 4). As we will detail in the next subsection, we transmitted three $42.7 \mathrm{~Gb} / \mathrm{s}$ channels in the Colchester-Ipswich link (or 'Ipswich' link), and two $128.1 \mathrm{~Gb} / \mathrm{s}$ channels in the Colchester-Chelmsford link ('Chelmsford' link). The 'Ipswich' link had a round-trip length of $83 \mathrm{~km}$, a loss of $12 \mathrm{~dB}$ for each direction, and an EDFA at the Ipswich site. It was $100 \%$ pre-compensated using slope-matched dispersion compensating modules (DCMs). The launched power into the DCM and the transmission fiber was $+2 \mathrm{dBm}$ and $+3 \mathrm{dBm}$ per channel, respectively.

The 'Chelmsford' link had a round trip length of $114 \mathrm{~km}$, a loss of $14 \mathrm{~dB}$ for each direction, and included an EDFA at the Chelmsford site. It was $80 \%$ pre-compensated and $20 \%$ postcompensated using slope-matched DCMs. The launched power into the DCM and the transmission fiber was $-1 \mathrm{dBm}$ and $+1 \mathrm{dBm}$ per channel, respectively.

In both links we used standard length fiber-based DCMs, and tailored dispersion by adding small spools of extra G.652 fiber in the lab. For the Chelmsford link, in which $\sim 2$ ps 


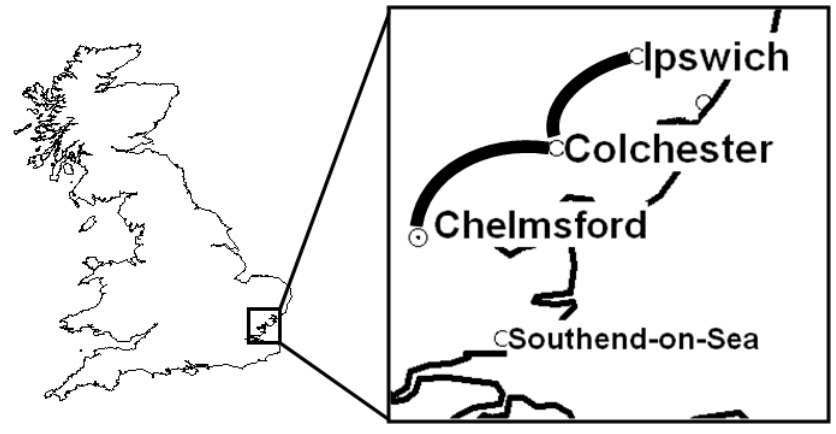

Fig. 4. The dark fiber network. Colchester - Chelmsford: $114 \mathrm{~km}$, round trip Colchester - Ipswich: $83 \mathrm{~km}$, round trip.

pulses were launched for transmitting $128.1 \mathrm{~Gb} / \mathrm{s}$ channels, we tailored the G.652 spool length to $+/-30 \mathrm{~m}$, and therefore, the second order group velocity dispersion (GVD) was compensated to within $+/-0.5 \mathrm{ps} / \mathrm{nm}$. It should be noted that due to some residual third order dispersion of $-0.3 \mathrm{ps} / \mathrm{nm}^{2}$ in this link, the two $128.1 \mathrm{~Gb} / \mathrm{s}$ channels had to also include individually tailored lengths.

The tailoring of the dispersion of the Ipswich link, in which $33 \%$ return-to-zero (RZ) $42.7 \mathrm{~Gb} / \mathrm{s}$ channels were transmitted, was much more relaxed. We did not employ any adaptive dispersion compensation in either link, and did not observe any substantial change of the dispersion in the Chelmsford link, even though the outside temperature varied by more than $12^{\circ} \mathrm{C}$ during the experiments. This is because the deployed fiber is, for the most part, buried in the ground, and its temperature does not change substantially on a daily basis. However, seasonal temperature variations, and, as a result, changes in the residual GVD of the fiber link are to be expected. For long term operation, therefore, adaptive dispersion compensation would be necessary.

The first order polarization mode dispersion (PMD) of the Chelmsford link was $\sim 1.0 \mathrm{ps}$, and the launched polarization of each individual signal was controlled. We observed both fast, but of limited extent; and slow (over many hours) changes to the pulse width. The system was able to cope with fast limited changes in differential group delay (DGD) due to PMD, and therefore, we only had to adjust the polarization controller of the launched signal only a few times a day. Nevertheless, in a real implementation active polarization control (principal state tracking) of the launched signal would be necessary.

\section{B. 42.7 / $128.1 \mathrm{~Gb} / \mathrm{s}$ signal generation}

For the experiments we generated three $33 \% \mathrm{RZ} 42.7 \mathrm{~Gb} / \mathrm{s}$ OOK signals, which were transmitted in the Ipswich link, and two $128.1 \mathrm{~Gb} / \mathrm{s}$ OOK OTDM signals (each with co-polarized tributaries) for the Chelmsford link. To generate the pulses for the $42.7 \mathrm{~Gb} / \mathrm{s}$ channels, three un-modulated continuous-wave (CW) laser diodes (LDs) at $\lambda_{1}=1547.7 \mathrm{~nm}, \lambda_{2}=1549.3 \mathrm{~nm}$, $\lambda_{3}=1550.9 \mathrm{~nm}$ (Table I), were input to an x-cut LN singledrive MZM driven by a sinusoidal signal at $21.35 \mathrm{GHz}$, and biased to produce $33 \% \mathrm{RZ}$ at $42.7 \mathrm{GHz}$. To generate the predata-encoded $42.7 \mathrm{GHz}$ pulses for the two OTDM channels we used two MLLs. The first MLL, centered at $\lambda_{\text {OTDM1 }}=1542$ $\mathrm{nm}$, was a $10.675 \mathrm{GHz}$ hybridly mode-locked laser diode (MLLD), with RMS jitter of $\sim 250$ fs (in $100 \mathrm{~Hz}-10 \mathrm{MHz}$ ), and FWHM pulse width of $\sim 2.5$ ps. Its rate was multiplied by four to reach $42.7 \mathrm{GHz}$, by a polarization maintaining (PM) fibre-based optical multiplexer (OMUX), to derive the same polarization for all multiplexed pulses, and accurate, stable pulse alignment. The second MLL, centered at $\lambda_{\text {OTDM2 }}=1556$ $\mathrm{nm}$, was a $42.7 \mathrm{GHz}$ hybridly mode-locked fibre laser (MLFL) with RMS jitter less than 70 fs (in $100 \mathrm{~Hz}-10 \mathrm{MHz}$ ). The pulse width was selected between two values, $\sim 1.4 \mathrm{ps}$ and $\sim 2.5 \mathrm{ps}$, on the instrument. For the first experiment, the $2.5 \mathrm{ps}$ FWHM pulse width was chosen, which is approx. $30 \%$ of the $7.8 \mathrm{ps}$ bit-period at $128.1 \mathrm{~Gb} / \mathrm{s}$. However, at this setting the laser produced a small leading pulse, which created a performance degradation in the system (see next subsection). In the second experiment we selected the narrower pulse, and with external filtering we brought the output pulse width to $2.1 \mathrm{ps}$.

TABLE I SIGNAL WAVELENGTHS

\begin{tabular}{|l|l|}
\hline$\lambda_{1}$ & $1547.7 \mathrm{~nm}$ \\
\hline$\lambda_{2}$ & $1549.3 \mathrm{~nm}$ \\
\hline$\lambda_{3}$ & $1550.9 \mathrm{~nm}$ \\
\hline$\lambda_{\text {OTDM } 1}$ & $1542 \mathrm{~nm}$ \\
\hline$\lambda_{\text {OTDM } 2}$ & $1556 \mathrm{~nm}$ \\
\hline
\end{tabular}

Due to equipment limitations, all five $42.7 \mathrm{GHz}$ signals (the two MLLs plus the three $33 \% \mathrm{RZ}$ ) were subsequently coupled into a single LN MZM for OOK data encoding. Therefore, the choice of wavelengths (chosen wavelengths listed in Table I) for the five signals was limited, and resulted in a large separation for the two OTDM channels. After encoding the five signals were demultiplexed. We used a separate OMUX to take the rate to $128.1(3 \mathrm{x} 42.7) \mathrm{Gb} / \mathrm{s}$ of each MLL-based $42.7 \mathrm{~Gb} / \mathrm{s}$ signal. This is because the fiber-based OMUX can only be optimized at a certain wavelength, due to the dispersion of its fiber. Since there are no OMUX products in the marketplace to provide 3-times multiplication, we constructed custom OMUXs, by using $40->80 \mathrm{~Gb} / \mathrm{s}$ standard OMUX product to take the rate to $2 \times 42.7 \mathrm{~Gb} / \mathrm{s}$, and coupling to its output one extra delayed copy of the original $42.7 \mathrm{~Gb} / \mathrm{s}$ data. The $40->80 \mathrm{~Gb} / \mathrm{s}$ stage was providing $2^{7}-1$ pseudorandom bit-sequence (PRBS) at $85.4 \mathrm{~Gb} / \mathrm{s}$, for $2^{7}-1$ PRBS at its input. In addition, we provided sufficient delay in the extra path to decorrelate the third tributary with either of the other two. However, it should be noted that the data pattern at $128.1 \mathrm{~Gb} / \mathrm{s}$ was not the standard PRBS $2^{7}-1$ pattern. Last, a polarizer with extinction better than $24 \mathrm{~dB}$ was connected at the output of each custom OMUX to guarantee co-polarized OTDM tributaries.

In order to evaluate the performance of the asynchronous retiming provided by the ADORE, and determine the data integrity of the scheme, we included guard-bands in the data pattern (Fig. 5). The data pattern of all five signal wavelengths (Table 1) at $42.7 \mathrm{~Gb} / \mathrm{s}$ consisted of a repeating $2^{7}-1$ PRBS of 


\begin{tabular}{|c|c|c|}
\hline Data block & $\begin{array}{l}\text { Guard } \\
\text { Band }\end{array}$ & Data block \\
\hline$\sim 1 \mathrm{~ms} \longrightarrow \sim 1 \mathrm{~ms} \longrightarrow$
\end{tabular}

Fig. 5. The data format used in all generated signals.

$1 \mathrm{~ms}$ duration, and a single truncated and modified $2^{19}-1$ PRBS serving as a $1 \mu$ s guard-band with mark ratio $52.5 \%$. There is no particular significance in the $2^{19}-1$ PRBS length we used. We used it simply because we found it easier to generate and modify. The $52.5 \%$ mark ratio however, was selected after testing a number of different mark ratios which had to satisfy the following two conditions: First, the mark ratio should be significantly different than $50 \%$ in order for the slow speed $(100 \mathrm{MHz})$ guard-band detection circuitry to detect a different power level for the signal envelope, and register it as the start of the guard-band (see section II.A). Second, the mark ratio should be close enough to $50 \%$ so that the DC imbalance was not affecting the operation of the $128.1 \mathrm{~Gb} / \mathrm{s} \mathrm{CRU}$.

\section{Experiment 1: Edge grooming, transmission, and tributary separation}

In the first experiment (Fig. 6), the three $42.7 \mathrm{~Gb} / \mathrm{s} \mathrm{33 \%} \mathrm{RZ}$ channels at wavelengths $\lambda_{1}, \lambda_{2}$, and $\lambda_{3}$ (Table I) were transmitted in Ipswich link (refer to Fig 3). They were then demultiplexed and entered a MEMS switch. Of these, $\lambda_{1}$ was selected to enter the ADORE unit of the WDM-to-OTDM subsystem. The ADORE was configured as in Fig. 2 (section II.A), including a $15 \mathrm{~dB}$ gain pre-amplifier for the data input with no optical band-pass filter. The $42.7 \mathrm{GHz}$ MLFL at $\lambda_{\text {OTDM2 }}$ provided the pulse trains needed for the WDM-toOTDM subsystem and therefore, the local clock signal in the WDM-to-OTDM was the same with the clock of the transmitter. However, the data phase at the ADORE input experienced a random drift, of up to a few tenths of 1 ps per second, with respect to the locally generated pulses from the MLFL, due to thermal fluctuations in the $83 \mathrm{~km}$ transmission fiber. The ADORE detected the guard-band in the data, and the switch controller allowed selection of the correct phase of the data for each $1 \mathrm{~ms}$-long data block, with switching taking place within a guard-band. The total switching time was consistently measured to be 440ns, and was, therefore, well within the $1 \mu$ s duration of the guard-band. In this way, data block integrity was assured during natural variations of input data phase in the dark fiber. For certain tests we used a computer controlled VODL at the ADORE input to provide deterministic and accelerated relative variation of input phase up to a maximum of 9 ps per second. The left eye in inset B, Fig. 6 shows the ADORE output eye over multiple controlled 1 bit (i.e. 23ps) sweeps, at step size of $0.1 \mathrm{ps,} \mathrm{of} \mathrm{the} \mathrm{input}$ phase. (The persistence on all eyes presented was approx. $9 \mathrm{~s}$. An optical sampling scope was used). During such controlled phase sweeps we recorded, in an error detector (ED) gated at the edges of the guard-band, error free operation (zero errors) down to $-27 \mathrm{dBm}$ power in a receiver placed at the ADORE output, suggesting an approximate penalty at $10^{-9}$ BER of $3-4$ $\mathrm{dB}$ with respect to the input signal to the ADORE. This penalty is due to eye closure (left eye in Fig. 6, inset B), and is in agreement with previous stand-alone testing [25].

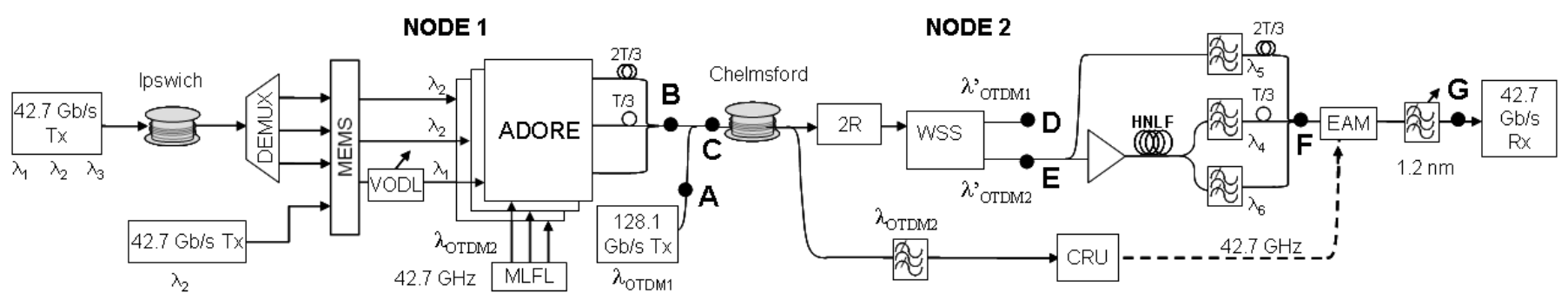

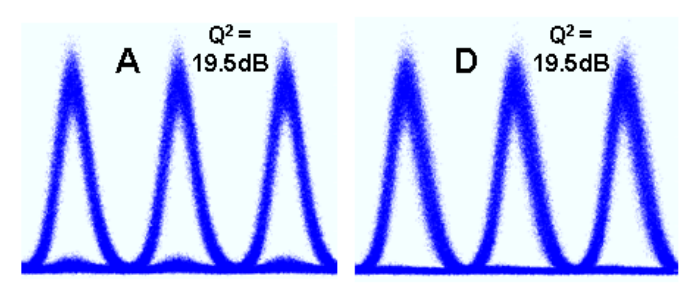
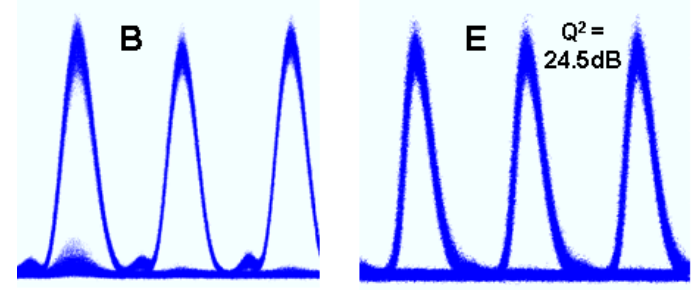
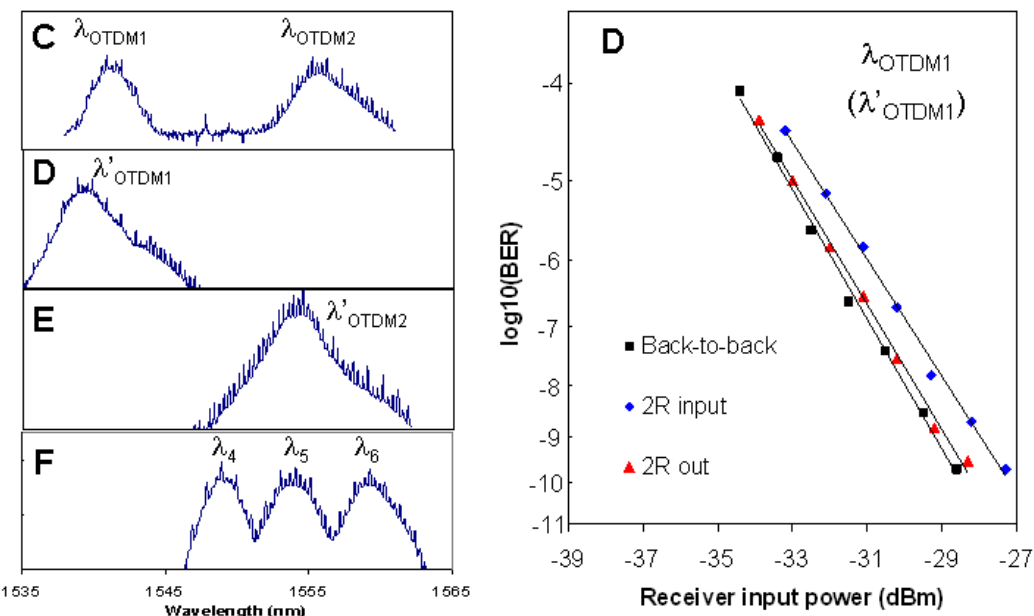

Fig. 6. Experiment 1 (Edge grooming, transmission, and tributary separation): Setup and results. Results at point G are shown separately, in Fig. 7. 
In addition to $\lambda_{1}$, two local channels at $\lambda_{2}$ were pulse-width adapted and wavelength converted to $\lambda_{\text {OTDM2 }}$ in the reduced ADORE versions, and interleaved together with the ADORE output to form the $\lambda_{\text {OTDM2 }} 128.1 \mathrm{~Gb} / \mathrm{s}$ OTDM channel at the WDM-to-OTDM output (inset B, Fig. 6). A polarizer at the output of the WDM-to-OTDM was guaranteeing co-polarized tributaries.

Furthermore, a second $128.1 \mathrm{~Gb} / \mathrm{s}$ OTDM channel at $\lambda_{\text {OтDM1 }}$ was generated at the transmitter using the higher jitter MLLD. Its eye is shown in inset A, Fig. 6. The $Q^{2}$ was 19.5 $\mathrm{dB}$. (All $\mathrm{Q}^{2}$ values presented were measured with the optical sampling scope). The two channels were subsequently launched into the Chelmsford link (spectrum at launch is in inset C, Fig. 6). After transmission, both OTDM channels were $2 \mathrm{R}$ regenerated (in the regenerator described in section II.C) by launching them in the same HNLF in opposite directions at approx. $30 \mathrm{dBm}$ power per channel. The $2 \mathrm{~nm}$ blue-shifted spectra of the regenerated channels can be seen in Fig. 6 , spectra insets $\mathrm{D}$, and $\mathrm{E}$. The regenerated $\lambda_{\text {OTDM } 1}$ was restored to its pre-transmission quality (eye inset D), according to $\mathrm{Q}^{2}$ (measured $\mathrm{Q}^{2}=19.5 \mathrm{~dB}$ ) and burst-mode biterror rate (BER) measurements (see BER plot in Fig. 6).

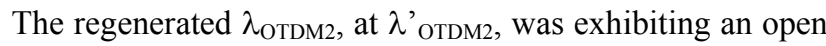
eye of $\mathrm{Q}^{2}=24.5 \mathrm{~dB}$, irrespectively of the input data phase to the ADORE (Fig. 6, inset E). This was subsequently OTDMto-WDM demultiplexed into wavelengths $\lambda_{4}=1549, \lambda_{5}=$ 1554 , and $\lambda_{6}=1559 \mathrm{~nm}$. The launched power into the HNLF was approx. $28 \mathrm{dBm}$. Fig. 6 , inset F, shows the spectrum of the three $128.1 \mathrm{~Gb} / \mathrm{s}$ copies, before EAM-demultiplexing. While the system was simultaneously demultiplexing all three tributaries, we filtered with a $1.2 \mathrm{~nm}$ FWHM filter each tributary and carried out burst-mode BER measurements, which are shown in Fig. 7 . The tributary at $\lambda_{4}$ belongs to the ADORE (i.e. it is the one that was generated by it), which was operating automatically while we were carrying out the BER measurements. Fig. 7 also shows the demultiplexed eyes. The noise that appears on the two sides of each demultiplexed eye is due to the $1.2 \mathrm{~nm}$ filter we used, which results in overlapped pulses due to imperfect extinction provided by the EAM. A broader filter is normally required but was unavailable. For comparison, the BER of the back-to-back EAM-demultiplexed $\lambda_{\text {OTDM2 }}$ channel is also provided. The maximum penalty is $2 \mathrm{~dB}$ at $10^{-9} \mathrm{BER}$. The degradation was mainly due to the presence of a small leading pulse from the MLFL (clearly visible in Fig. 6, inset B), that was spreading during transmission into adjacent pulses causing beating, and thus affecting the stability of the $128.1 \mathrm{~Gb} / \mathrm{s}$ CRU. In fact, because of this influence, the CRU operation was more stable when the clock was derived from the $128.1 \mathrm{~Gb} / \mathrm{s}$ before the $2 \mathrm{R}$ regenerator. This is because the beating mentioned was translated in increased jitter of the $2 \mathrm{R}$ regenerated signal - as predicted in [37] - further destabilizing the CRU if connected at the output of the $2 \mathrm{R}$ regenerator.

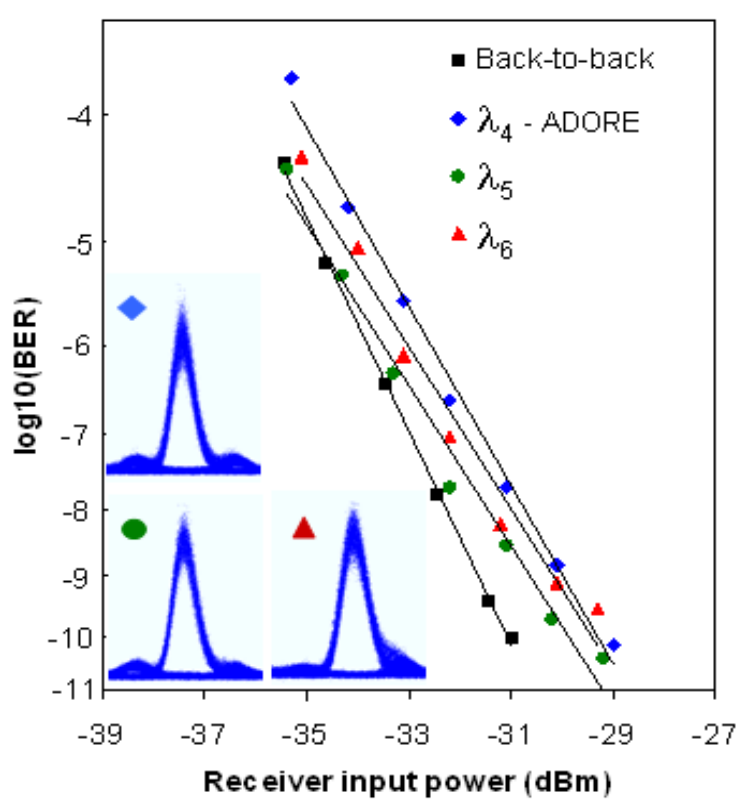

Fig. 7. BER measurements and eye diagrams for the three demultiplexed tributaries in the first experiment, at point G of Fig. 6.

\section{OTDM transmission, tributary separation, WDM bridge, and re-aggregation}

In the second experiment (Fig. 8), we selected the narrower pulse output from the MLFL (see section IV.B) and filtered it externally to get $2.1 \mathrm{ps}$ FWHM pulses at $\lambda_{\text {OTDM2 }}$. Unlike the previous experiment, there was no small leading pulse from the MLFL, as a result of this change. The $128.1 \mathrm{~Gb} / \mathrm{s}$ OTDM at $\lambda_{\text {OTDM2 }}$ from the transmitter (Fig. 8 inset A) was launched in the Chelmsford link. After transmission (Fig. 8 inset B) it was $2 \mathrm{R}$ regenerated with $2 \mathrm{~nm}$ blue-offset filtering in the regenerator described in section II.C, by launching approx. 30 $\mathrm{dBm}$ signal power in the HNLF. A $\mathrm{Q}^{2}=25.5 \mathrm{~dB}$ was achieved (Fig. 8 inset $\mathrm{C}$ ). The regenerated signal at $\lambda^{\prime}{ }_{\text {OTDM } 2}=1554 \mathrm{~nm}$ was then input to the OTDM-WDM demultiplexer. The launched power into the HNLF was approx. $28 \mathrm{dBm}$ and the broadened spectrum is shown in Fig. 8, inset D. A $5 \mathrm{~nm}$ offset filtering was applied either side of the centre, creating two $128.1 \mathrm{~Gb} / \mathrm{s}$ copies of the original channel (Fig. 8 insets E, F) at $\lambda_{4}=1549$, and $\lambda_{6}=1559 \mathrm{~nm}$, with $\mathrm{Q}^{2} 23.5 \mathrm{~dB}$ and $24 \mathrm{~dB}$, respectively. These two copies together with the original signal at $\lambda_{\text {' }}$ отDм2 $=1554 \mathrm{~nm}$, which we now call $\lambda_{5}$ (i.e. $\lambda_{5}=$ $1554 \mathrm{~nm}$ ), were combined and input to the EAM gate, driven by the recovered clock at $42.7 \mathrm{GHz}$. The total power into the EAM was $6 \mathrm{dBm}$, and the polarization was optimized for each of the three channels. In addition, tunable delay lines were used (shown as fixed delays in Fig. 8) in order to simultaneously demultiplex a different tributary from each of the three $128.1 \mathrm{~Gb} / \mathrm{s}$ copies. In this experiment, the input signal to the CRU unit was taken by tapping off the output of the $2 \mathrm{R}$ regenerator. The CRU RMS jitter was calculated based on single side-band phase noise measurements, and was less than $50 \mathrm{fs}$ in $100 \mathrm{~Hz}-10 \mathrm{MHz}$ bandwidth. 

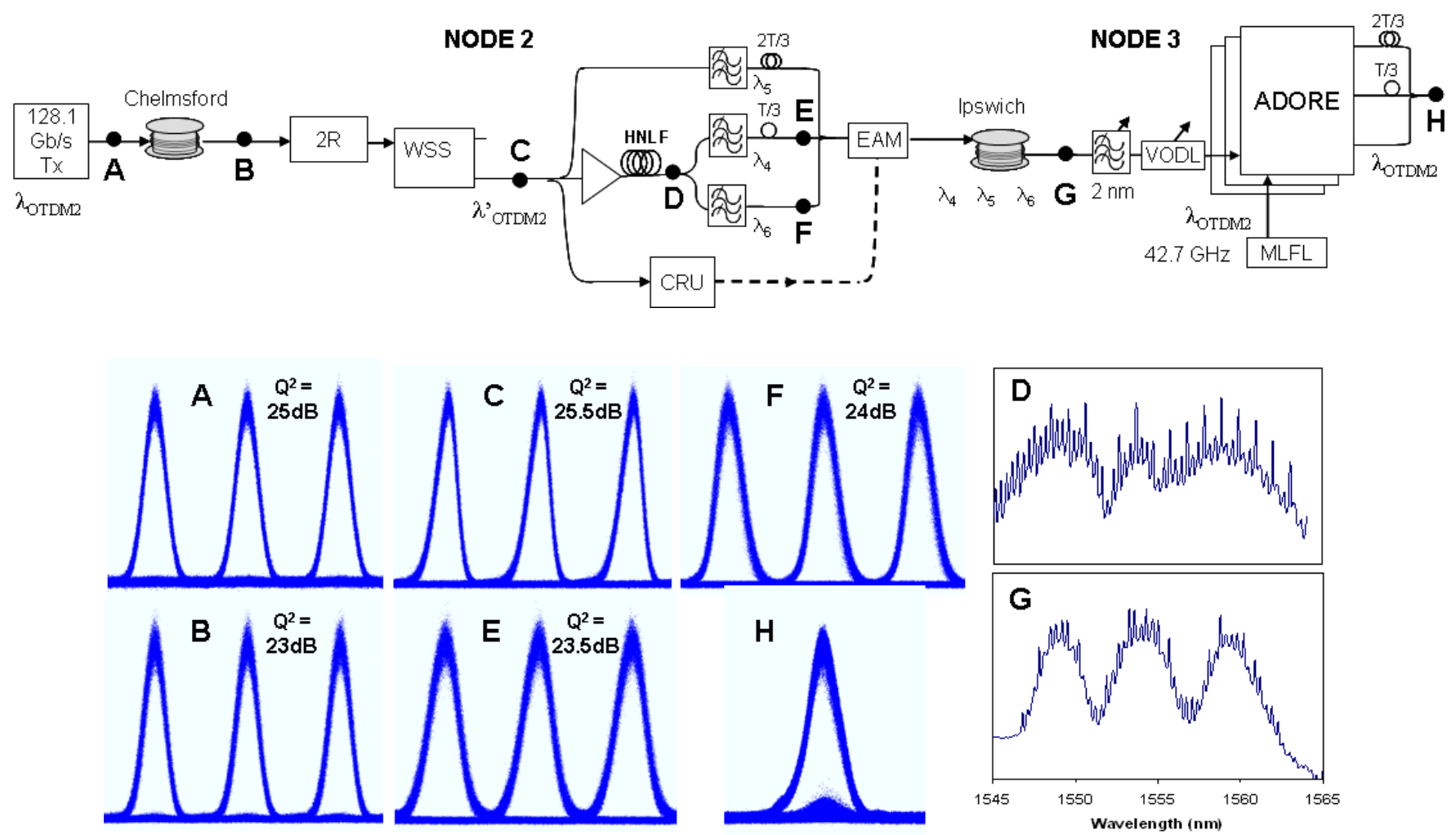

Fig. 8. Experiment 2 (OTDM transmission, tributary separation, WDM bridge, and re-aggregation): Setup and results. BER results at point G are shown in Fig. 9.

All three demultiplexed channels were transmitted in the Ipswich link. (Fig. 8, inset $G$ shows the spectrum after transmission). The channels were subsequently demultiplexed using $2 \mathrm{~nm}$ FWHM filters, and burst-mode BER measurements are shown in Fig. 9, along with the eyes of the three tributaries in the receiver. It can be seen that, compared with back-to-back measurements (by demultiplexing $\lambda_{\text {OTDM2 } 2}$ at the transmitter, using the same EAM, driven with the same RF amplitude, for fair comparison), there is no penalty in the $\lambda_{5}$, and $\lambda_{6}$ tributaries. (It should be noted that the Ipswich link introduced a less than $0.5 \mathrm{~dB}$ penalty to the signal). In addition, $\lambda_{4}$ shows a very small $0.5 \mathrm{~dB}$ penalty at $10^{-9}$ BER, but with an error floor (below $10^{-12}$ ). We attribute this to insufficient broadening in the OTDM-WDM HNLF in the shorter wavelength side (Fig. 8, inset D), which reflects a significant departure from the optimum transfer function for the HNLF [33].

The $\lambda_{6}$ channel was then input to the ADORE unit. The clock pulses were generated by the MLFL at $\lambda_{\text {OTDM2 }}$, and the data input to the ADORE included a $15 \mathrm{~dB}$ gain pre-amplifier with no optical band-pass filter, as in the first experiment. In this experiment, the signal was experiencing phase changes due to its transmission in both Chelmsford and Ipswich link, since $\lambda_{6}$ data originates in the $\lambda_{\text {OTDM2 }}$ OTDM channel launched in the Chelmsford link. The ADORE output eye can be seen in Fig. 8, inset $\mathrm{H}$, and was confirmed to be error free (zero errors) for all input data phases, by performing controlled sweeps of the phase using the computer controlled
VODL, as in the first experiment. Three ADORE units would be required to aggregate the traffic carried by $\lambda_{4}, \lambda_{5}$, and $\lambda_{6}$, and form a new OTDM channel for transmission in the new OTDM domain.

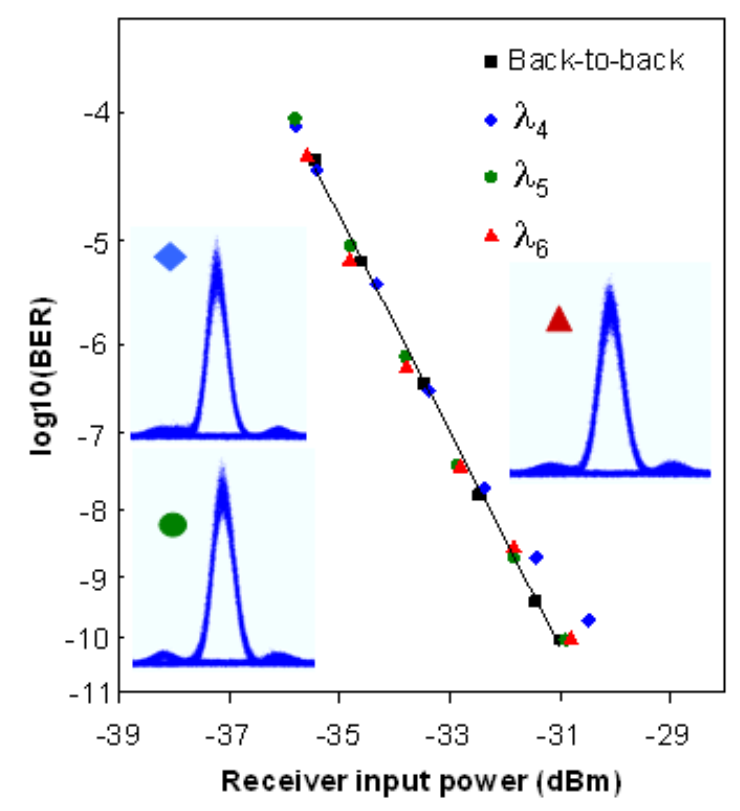

Fig. 9. BER measurements and eye diagrams for the three demultiplexed tributaries in the second experiment, at point G, Fig. 8. 


\section{DisCUSSION AND CONCLUSIONS}

During all measurements in the two experiments, we were only controlling variable delay lines, in order to compensate for thermal drifts in the lab setups, especially in the two transmultiplexing subsystems. In particular, the OTDM-toWDM would require thermally stabilized packaging, and the light-paths in the WDM-to-OTDM should preferably be made of light waveguides rather than fiber. An additional requirement for the WDM-to-OTDM subsystem concerns the length of each individual tributary path, from the local pulse source to the multiplexed output. These paths would need to be kept to within a few centimeters long if thermal fluctuations in the individual paths are not to cause output power fluctuations, owing to small overlaps between adjacent pulses at the output OTDM channel [38]. However, given the current ADORE implementation, such short path lengths are unattainable. Therefore, it may be necessary to include a gate at the output of this subsystem, in order to construct a common phase for all tributaries [39].

We also found that the MLL source quality is critical for good performance. In addition, tracking of the principal state of polarization and adaptive chromatic dispersion compensation would be required in a real deployment.

Furthermore, the OTDM-to-WDM subsystem, with the particular HNLF we used in the experiments, requires signals with very low amplitude noise, in order to produce wavelength converted copies of low jitter. This clearly reflects the HNLF specification. With the $2 \mathrm{R}$ regenerator at its input the OTDM-to-WDM produced excellent performance.

An issue that was not addressed in this work concerns channel identification. A possible solution to this problem can be found in [40]. In addition, the 440 ns cross-bar switch that was used in the ADORE can potentially affect subsequent clock recovery. A nanosecond-fast switch should solve this problem. Last, the proposed regenerator changes the signal wavelength, with two possibilities: to shorter or longer wavelength. As a result, selective regeneration of OTDM channels could result in wavelength blocking at the node output. It may be necessary, therefore, to regenerate all input OTDM channels to a node, using the concept of the multi wavelength regenerator, in order to effect a uniform wavelength shift on all channels. Such uniform shift may be cancelled out at the output of the same node, if an output regenerator is placed, with offset filtering applied on the opposite side of its broadened spectrum.

Although we presented experimental results at $128.1 \mathrm{~Gb} / \mathrm{s}$, our concept is scalable to much higher bit-rates. This is because, first, the ADORE operates on tributaries. Second, the OTDM-to-WDM can be implemented with a different technique, including pulsed source as in [29]. And third, the $2 \mathrm{R}$ regenerator is all-optical. Regarding the latter, in [41] we have numerically studied the scalability limit of the $2 \mathrm{R}$ regenerator system as the repetition rate increases. Carefully selecting from the design map reported in [33] the fiber and input signal parameters in order to achieve the same regenerative properties, it is possible to increase the repetition rate up to 640Gbit/s without any extra degradation due to undesired cross-talk with the Rayleigh backscattered signal.

In addition, our concept provides a port-scalable solution, since it is limited only by the dimension of the MEMS switch fabric. Bursty traffic on a per tributary basis [17] could also be supported by the transmultiplexing technologies presented. In this case, the MEMS switch should be replaced by a much faster switch, suitable for routing bursts. However, fast switch fabrics have limited port scalability.

Furthermore, the ADORE, as a concept, is applicable to a host of single-carrier (multi-level, and including phase sensitive) modulation formats. With this in mind, the only real limitation of the scheme is the need for adaptation of the data format at network edge to include guard-bands. This would require $\mu \mathrm{s}$-long electronic buffering at the edge.

In conclusion, we have demonstrated in the field a concept for OTDM meshed networking of potentially global reach, and with near $100 \%$ channel utilization based on $1 \mathrm{~ms}$ data blocks separated by $1 \mu$ s guard-bands. Our results confirm, first, the data integrity of the asynchronous retiming scheme in both cases of edge traffic grooming and OTDM domain interconnection and, second, the potential of the all-optical techniques used for signal regeneration and wavelength conversion in small scale OTDM domains.

\section{ACKNOWLEDGMENT}

The authors thank Agilent Technologies, U.K., for the loan of the $50 \mathrm{GHz}$ power spectrum analyzer, and the Furukawa Electric Company for the loan of the HNLF.

\section{REFERENCES}

[1] P. J. Winzer, and R. J. Essiambre, "Advanced Modulation Formats for High-Capacity Optical Transport Networks”, J. Lightw. Technol., vol. 24, no. 12, pp. 4711-4728, Dec. 2006.

[2] G. Charlet, "Progress in Optical Modulation Formats for High-Bit Rate WDM Transmissions", IEEE J. Sel. Topics Quantum Electron., vol. 12, no. 4, pp. 469-483, Jul./Aug. 2006.

[3] J. Armstrong, "OFDM for Optical Communications", J. Lightw. Technol., vol. 27, no. 3, pp. 189-204 Feb. 2009.

[4] Q. Yang, Y. Tang, Y. Ma, and W. Shieh, ”Experimental Demonstration and Numerical Simulation of 107-Gb/s High Spectral Efficiency Coherent Optical OFDM", J. Lightw. Technol., vol. 27, no. 3, pp. 168176, Feb. 2009

[5] D. A. B. Miller, "Recent Advances in Germanium Quantum Well Structures - A New Modulation Mechanism for Silicon-Compatible Optics", presented at the Optical Fiber Commun. Conf. (OFC), Anaheim, CA, 2007, Paper OTuD4

[6] A.A.M. Saleh, and J. M. Simmons, "Evolution Toward the NextGeneration Core Optical Network”, J. Lightw. Technol., vol. 24, no. 9, pp. 3303-3321, Sep. 2006.

[7] B. Pratt, "Multi-Layer Switching in Packet Optical Transport Systems", in Proc. Optical Fiber Commun. Conf. (OFC/NFOEC), San Diego, CA, 2008, Paper NWF2.

[8] T. Bonald, S. Oueslati-Boulahia, J. Roberts, "IP Traffic and QoS Control: The Need for a Flow Aware Architecture", in Proc. World Telecommunication Congress, 2002, Paris, France.

[9] H. G. Weber, R. Ludwig, S. Ferber, C. Schmidt-Langhorst, M. Kroh, V. Marembert, C. Boerner, and C. Schubert, "Ultrahigh-Speed OTDM- 
Transmission Technology”, J. Lightw. Technol., vol. 24, no. 12, pp. 4616-4627, Dec. 2006.

[10] C. Schmidt-Langhorst, R. Ludwig, D.-D. Groß, L. Molle, M. Seimetz, R. Freund, and C. Schubert, "Generation and Coherent Time-Division Demultiplexing of up to $5.1 \mathrm{~Tb} / \mathrm{s}$ Single-Channel 8-PSK and 16-QAM Signals", presented at the Optical Fiber Commun. Conf. (OFC), San Diego, CA, 2009, Paper PDPC6.

[11] M. Nakazawa and T. Hirooka, "Terabit OTDM transmission - Key challenges", in 2007 Digest of the IEEE, LEOS Summer Topical Meetings, 23-25 Jul. 2007, Portland, OR, pp. 230-231, Paper ME3.3.

[12] H.G. Weber, S. Ferber, M. Kroh, C. Schmidt-Langhorst, R. Ludwig, V. Marembert, C. Boerner, F. Futami, S. Watanabe, and C. Schubert, "Single channel 1.28 Tbit/s and 2.56 Tbit/s DQPSK transmission", Electron. Lett., vol. 42, no. 3, pp. 178-179, Feb. 2006.

[13] R. Nejabati, G. Zervas, G. Zarris, Y. Qin, E. Escalona, M. O’Mahony, and D. Simeonidou, "Multigranular Optical Router for Future Networks", OSA J. Optical Networking, vol. 7, no. 11, pp.914-927, Nov 2008.

[14] J. P. Turkiewicz, E. Tangdiongga, G. Lehmann, H. Rohde, W. Schairer, Y. R. Zhou,E. S. R. Sikora, A. Lord, D. B. Payne, G.-D. Khoe, and H. de Waardt, "160 Gb/s OTDM Networking Using Deployed Fiber", J. Lightw. Technol., vol. 23, no. 1, pp. 225-235, Jan. 2005.

[15] S. Spaelter, M. Heid. S. L. Jansen, G. Lehmann, E. Meissner, and B. Lankl, "Ultra Fast Switching in OTDM Networks", in Proc. 28th Eur. Conf. Optical Commun. (ECOC), Copenhagen, 2002, vol. 4, Paper 11.4.1.

[16] G. Zarris, L. M. Sadeghioon, C. G. Leburn, H.-D. Jung, K. M. Guild, D. Simeonidou, and M. O'Mahony, "Applications of Ultra-Short Pulse Sources in OTDM Networks", in Proc. Photonics in Switching, Heraklion, Crete, Oct. 2006, Paper O 9.1.

[17] A. D. Ellis, D. Cotter, S. Ibrahim, R.Weerasuriya, C. W. Chow, J. Leuthold, W. Freude, S. Sygletos, P. Vorreau, R. Bonk, D. Hillerkuss, I. Tomkos, A. Tzanakaki, C. Kouloumentas, D. J. Richardson, P. Petropoulos, F. Parmigiani, G. Zarris, and D. Simeonidou, "Optical Interconnection of Core and Metro Networks", OSA J. Optical Networking, vol. 7, no. 11, pp.928-935, Nov.2008.

[18] D. Cotter, and A. D. Ellis, "Asynchronous Digital Optical Regeneration and Networks", J. Lightw. Technol., vol. 16, no. 12, pp. 2068-2080, Dec. 1998.

[19] I. D. Phillips, P. Gunning, A. D. Ellis, J. K. Lucek, D. G. Moodie, A. E. Kelly, and D. Cotter, "10-Gb/s Asynchronous Digital Optical Regenerator”, IEEE Photon. Technol. Lett., vol. 11, no. 7, pp. 892-894, Jul. 1999.

[20] D. Norte, and A. E. Willner, "All-Optical Data Format Conversions and Reconversions Between the Wavelength and Time Domains for Dynamically Reconfigurable WDM Networks", J. Lightw. Technol., vol. 14, no. 6, pp. 1170-1182, Jun. 1996.

[21] P. Vorreau, D. Hillerkuss, F. Parmigiani, S. Sygletos, R. Bonk, P. Petropoulos, D. Richardson, G. Zarris, D. Simeonidou, D. Klonidis, I. Tomkos, R. Weerasuriya, S. Ibrahim, A. Ellis, R. Morais, P. Monteiro, S. Ben Ezra, S. Tsadka, W. Freude, J. Leuthold, "2R/3R Optical Grooming Switch with Time-Slot Interchange", in Proc. Eur. Conf. Optical Commun. (ECOC), Brussels, 2008, Paper PDP Th.3.F.4.

[22] P. Vorreau, S. Sygletos, F. Parmigiani, D. Hillerkuss, R. Bonk, P. Petropoulos, D. J. Richardson, G. Zarris, D. Simeonidou, D. Klonidis, I. Tomkos, R. Weerasuriya, S. Ibrahim, A. D. Ellis, D. Cotter, R. Morais, P. Monteiro, S. Ben Ezra, S. Tsadka, W. Freude, J. Leuthold, "Optical Grooming Switch with Regenerative Functionality for Transparent Interconnection of Networks", OSA Opt. Express, vol. 17, no. 17, pp.15173-85, Aug. 17, 2009

[23] S. K. Ibrahim, D. Hillerkuss, R. Weerasuriya, G. Zarris, D. Simeonidou, J. Leuthold, A.D. Ellis, "Novel 42.65 Gbit/s Dual Gate Asynchronous Digital Optical Regenerator Using a Single MZM", in Proc. Eur. Conf. Optical Commun. (ECOC), Brussels, 2008, Paper Tu.4.D.3.

[24] R. Weerasuriya, S. K. Ibrahim, G. Zarris, D. Simeonidou, A. D. Ellis, and D. Cotter, "Performance Characterization of a $42.65 \mathrm{Gbit} / \mathrm{s}$ Dual Gate Asynchronous Digital Optical Regenerator Using a Single MZM", Electron. Lett., vol. 45, no. 12, pp. 642-643, Jun. 2009.

[25] G. Zarris, P. Vorreau, D. Hillerkuss, S.K. Ibrahim, R. Weerasuriya, A.D. Ellis, J. Leuthold, and D. Simeonidou, "WDM-to-OTDM Traffic Grooming by means of Asynchronous Retiming", in Proc. Optical Fiber Commun. Conf. (OFC), San Diego, CA, 2009, Paper OThJ6.
[26] P. V. Mamyshev, "All-optical data regeneration based on self-phase modulation effect," in Proc. 24th Eur. Conf. Optical Commun. (ECOC), Madrid, 1998, vol. 1, pp. 475-476.

[27] R. Morais, R. Meleiro, P. Monteiro, and P. Marques, "OTDM-to-WDM Conversion based on Wavelength Conversion and Time Gating in a Single Optical Gate", in Proc. Optical Fiber Commun. Conf. (OFC), San Diego, CA, 2008, Paper OTuD5.

[28] H. Sotobayashi, and W. Chujo, "Photonic gateway: TDM-to-WDM-toTDM conversion and reconversion at 40Gbit/s (4 channels X 10 Gbit/s)", J. Opt. Soc. Am. B, vol. 19, no. 11, pp. 2810-2816, Nov.2002.

[29] C.-S. Brès, A. O. J. Wiberg, B. P.-P. Kuo, J. M. Chavez-Boggio, C.F. Marki, N. Alic, and S. Radic, "Single-Gate 320-to-8x40 Gb/s Demultiplexing", presented at Optical Fiber Commun. Conf. (OFC), San Diego, CA, 2009, Paper PDPA4.

[30] F. Cisternino, R. Girardi, S. Romisch, R. Calvani, E. Riccardi, and P. Garino, "A novel approach to pre-scaled clock recovery in OTDM systems," in Proc. 24th Eur. Conf. Optical Commun. (ECOC), Madrid, 1998, vol. 1, pp. 477-478.

[31] J. Lasri, P. Devgan, R. Tang, and P. Kumar, "Ultralow timing jitter 40$\mathrm{Gb} / \mathrm{s}$ clock recovery using a self-starting optoelectronic oscillator," IEEE Photon. Technol. Lett., vol. 16, no. 1, pp. 263-265, Jan. 2004.

[32] F. Parmigiani, P. Vorreau, L. Provost, K. Mukasa, M. Takahashi, M. Tadakuma, P. Petropoulos, D. J. Richardson, W. Freude, and J. Leuthold, "2R regeneration of two $130 \mathrm{Gbit} / \mathrm{s}$ channels within a single fiber", in Proc. Optical Fiber Commun. Conf. (OFC), San Diego, CA, 2009, Paper JThA56.

[33] L. Provost, C. Finot, K. Mukasa, P. Petropoulos, and D. J. Richardson, "Design scaling rules for 2R-optical self-phase modulation-based regenerators", OSA Opt. Express, vol. 15, no. 8, pp. 5100-5113, Apr. 2007.

[34] J. F. DeNatale, R. L. Borwick, C. Tsai, P. A. Stupar, Y. Lin, R. A. Newgard, R. W. Berquist, and M. Zhu, "Compact, low-power chip-scale atomic clock", in Proc. IEEE/ION, Position, Location, and Navigation Symposium, Monterey, CA, 5-8 May 2008, pp. 67-70.

[35] M. Sexton and A. Reid, "Transmission Networking: SONET and the SDH", Artech House, 1992.

[36] G. Zarris, F. Parmigiani, E. Hugues-Salas, R. Weerasuriya, D. Hillerkuss, N. Amaya-Gonzalez, M. Spyropoulou, P. Vorreau, R. Morais, S.K. Ibrahim, D. Klonidis, P. Petropoulos, A.D. Ellis, P. Monteiro, A. Tzanakaki, D. Richardson, I. Tomkos, R. Bonk, W. Freude, J. Leuthold, and D. Simeonidou, "Field Trial of WDM-OTDM Transmultiplexing employing Photonic Switch Fabric-based Buffer-less Bit-interleaved Data Grooming and All-Optical Regeneration”, presented at Optical Fiber Commun. Conf. (OFC), San Diego, CA, 2009, Paper PDPC10.

[37] L. Provost, F. Parmigiani, P. Petropoulos, D. J. Richardson, "Investigation of Timing Jitter Reduction in a bidirectional 2R AllOptical Mamyshev Regenerator", in Proc. Optical Fiber Commun. Conf. (OFC), San Diego, CA, 2008, Paper OThJ4.

[38] T. Ohara, H. Takara, I. Shake, T. Yamada, M. Ishii, I. Ogawa, M. Okamoto, and S. Kawanishi, "Highly Stable 160-Gb/s OTDM Technologies Based on Integrated MUX/DEMUX and Drift-Free PLLType Clock Recovery", IEEE J. Sel. Topics Quantum Electron., vol. 13, no. 1, pp. 40-48, Jan./Feb. 2007.

[39] B.-E. Olsson, L. Rau, and D. J. Blumenthal, "WDM to OTDM Multiplexing Using an Ultrafast All-Optical Wavelength Converter", IEEE Photon. Technol. Lett., vol. 13, no. 9, pp. 1005-1007, Sep. 2001.

[40] M. Galili, L. K. Oxenløwe, A. T. Clausen, and P. Jeppesen, "320 Gbit/s Simultaneous Clock Recovery and Channel Identification”, Eur. Conf. Optical Commun. (ECOC), Berlin, Germany, Sep. 2007, Paper 5.3.2.

[41] F. Parmigiani, L. Provost, P. Petropoulos, D. J. Richardson, "Multiwavelength all-optical regeneration techniques" (Invited), IEEE/LEOS Summer Topicals, 20-22 Jul. 2009, Newport Beach, CA.

George Zarris received a BSc in physics from the University of Patras, Greece in 1993, an MSc in the physics of laser communications from the University of Essex, U.K. in 1996, and an MBA from Imperial College of Science, Technology and Medicine, U.K. in 2009.

In 1997 he joined Alcatel Submarine Networks, where he lead a team in the product development department in the design and development of a number 
of optical sub-systems, including the first undersea optical add-drop multiplexer, and the first $980 \mathrm{~nm}$ pumped undersea EDFA. During a secondment in 1999 in Alcatel, Villarceaux, France he worked on the system design of WDM transmission. In 2000 he joined Ilotron, an optical networking startup. He subsequently joined Ditech Communications Europe in 2001, where he held a senior engineering position and contributed in the system design of an optical cross-connect. Since 2004 he has been a technical member of the Photonic Networks Laboratory at the University of Essex, U.K., where he is also working toward a $\mathrm{PhD}$ degree. His current research interests include high-speed optical transmission and the evolution of optical networking for the transport of high-speed ethernet. $\mathrm{Mr}$ Zarris has (co)authored several publications and six patent applications, relating to optical communications.

Norberto Amaya Gonzalez was born in Tunja, Colombia in 1976. He obtained his B.Sc. in electronic engineering from the Universidad Distrital, Bogotá, Colombia in 2000 and his MSc in telecommunication and information systems from the University of Essex U.K. in 2005.

He joined Celumóvil (later Bellsouth) in 1998 in the Network Design and Optimization Department, Bogotá, Colombia while a student at the Universidad Distrital. From 2005 to 2007, he was employed as a senior capacity and support engineer with Orange Plc, Bristol, U.K, working on GSM/UMTS capacity planning and provisioning. In 2007 he joined Telefonica as a senior RF engineer working on TDMA/GSM/CDMA network planning and optimization. He is currently working toward a Ph.D. degree in optical networks at the University of Essex, U.K. He is a member of the Photonic Networks Laboratory at the University of Essex and his current research interests include high-speed optical transmission and transparent optical networks.

Ruwan Weerasuriya was born in Galle, Sri Lanka, in 1976. He received the B.Sc.Eng degree in 2002 from University of Moratuwa, Sri Lanka. From 2002 to 2006, he was with the Dialog Telekom Ltd, working on Terrestrial, Satellite Transmission and Network Monitoring Systems. In 2006 he moved to the UK for higher education and received the M.Sc. degree in 2007, from University of Nottingham, U.K. He is currently pursuing the Ph.D. degree at Tyndal National Institute, University College Cork, Ireland. He is a member of the Photonics System Group, Tyndall National Institute and his research interests include study of long-haul optical transmission systems, fiber nonlinearities and their applications and optical regeneration methods in high speed optical networks.

Francesca Parmigiani was born in Milan, Italy. She graduated with the degree in electronic engineering at Politecnico di Milano, Milano, Italy, in 2002, and received the Ph.D. degree in optical communication systems at the Optoelectronics Research Centre (ORC), University of Southampton, Southampton, U.K in 2006. She is currently a Research Fellow at the ORC. Her research interests include ultra-fast all-optical sampling techniques, pulse shaping using specialized fiber Bragg gratings, and all-optical nonlinear processing and switches mainly in optical fibers.

Dr Parmigiani is a member of the Optical Society of America (OSA).

Maria Spyropoulou was born in Tripoli, Greece. She holds a diploma in applied mathematics and physical sciences from the National Technical University of Athens, Greece (2004) and a M.Sc. degree in communication systems and signal processing from the University of Bristol, UK (2005).

She has joined the high speed networks and optical communications group of the Athens Information Technology institute as a research scientist since February 2006 and she is pursuing a Ph.D. degree at the Aristotle University of Thessaloniki, Greece. Her main research interests lie in the field of high speed all-optical signal processing subsystems for wavelength conversion, regeneration, clock recovery based on (quantum-dot)-SOAs.

Selwan K. Ibrahim (M'05) received his B.Sc. and M.Sc. degrees in Electronics and Communication Engineering from the University of Baghdad, Iraq, in 1999 and 2002, respectively, and the Ph.D. degree (Dr.-Ing.) in Electrical Engineering from the University of Paderborn, Germany, in 2007. His Ph.D. work was focused on the study of multilevel modulation formats for high speed digital optical communication systems. He joined the Chair for Optical Communications and High-Frequency Engineering in the Department of Electrical Engineering, University of Paderborn, Germany, as a Graduate Student/Research Assistant in the end of 2002, and obtained a scholarship from the Graduate School of Dynamic Intelligent Systems at the University of
Paderborn for the period 2003-2006. In December 2007 he joined the Photonic Systems Group as a Postdoctoral Researcher. His current research interest is in the area of Optical Communications involving coherent WDM transmission, advanced modulation formats, and optical networks. He is a member of the IEEE and IEEE Photonics Society.

Dr. Andrew Ellis was born in Underwood, England in 1965 and gained a BSc in Physics with a minor in mathematics from the University of Sussex, Brighton, England in 1987. He was awarded his $\mathrm{PhD}$ in Electronic and Electrical Engineering from The University of Aston in Birmingham, Birmingham, England in 1997 for his study on All Optical Networking Beyond $10 \mathrm{Gbit} / \mathrm{s}$.

He previously worked for British Telecom Research Laboratories as a Senior Research Engineer investigating the use of optical amplifiers and advanced modulation formats in optical networks and the Corning Research Centre as a Senior Research Fellow where he led activities in optical component characterisation. Currently, he heads the Transmission and Sensors Group at the Tyndall National Institute in Cork, Ireland, where he is also a member of the Department of Physics, University College Cork. He research interests include the evolution of core and metro networks, and the application of photonics to sensing.

Dr Ellis is a member of the Institute of Physics and the Institute of Engineering Technology, and is a Chartered Physicist. He acts as a reviewer for IEEE Journal of Lightwave Technology and Photonics Technology Letters and has published over 100 journal papers and over 20 patents in the field of Photonics.

Rui Morais was born in Lisbon in 1976. He received his diploma and M.Sc. degrees in Applied Physics from the Science Faculty of the University of Porto, in 1999 and 2003, respectively. Currently he is a Systems Architect at NOKIA SIEMENS Networks for DWDM Transport Products. He is also with the optoelectronics unit of INESC-Porto and he is a Ph.D. student from the Science Faculty of the University of Porto. Previously he was a researcher at Multiwave Photonics S.A.. His current research interests include Photonic Integrated Circuits and devices, all-optical signal processing, fibre and semiconductor optical nonlinearities.

Paulo Monteiro was born in Coimbra, Portugal in 1964. He received the diploma and doctoral $(\mathrm{PhD})$ degrees in electronics and telecommunications from the University of Aveiro and the M.Sc. degree from the University of Wales, UK. He is Optical Networks Technology Manager at Transport, Aggregation and Fixed Access Department of Nokia Siemens Networks. He is also Associate Professor at the University of Aveiro and researcher at the Instituto de Telecomunicações. His main research interests include High Speed Communications for Access and Core Optical Networks; Fixed-Mobile Convergence. He has acted as a reviewer of the IEEE Journal of Lightwave Technology, IEE Electronics Letters; ETRI Journal and OSA Journal of Optical Networking (JON); SPIE Optical Engineering. He has participated in several national and European projects and his currently the project coordinator of the Large-scale integrating project FUTON (FP7 ICT-2007215533). He has authored/co-authored more than 18 patent applications and over 200 refereed papers and conference contributions.

Dr. Periklis Petropoulos was born in Patras, Greece. He graduated from the Department of Electrical Engineering and Information Technology, University of Patras, Greece in 1995. He received the MSc degree in Communications Engineering from UMIST, UK in 1996 and the $\mathrm{PhD}$ degree in Optical Telecommunications from the Optoelectronics Research Centre (ORC), University of Southampton, UK in 2000.

Dr. Petropoulos is currently appointed a Reader at the ORC. His particular areas of interests and expertise lie in the fields of optical communications and nonlinear fibre technology. Within the Optical Fibre Communications group at the ORC he is working on such areas as all-optical processing and switching in optical fibres; pulse manipulation for optical communications using fibre Bragg gratings, including applications in optical correlation systems for the implementation of optical code-division multiple access and optical packet switched systems; silica and compound glass holey fibres and their nonlinear applications; and fibre lasers. His research has produced more than 200 papers in journals and conferences in the field of optical physics and optical communications.

Dr. Petropoulos is a Member of the Optical Society of America. 
David J. Richardson was born in Southampton, England in 1964 and obtained his B.Sc. and Ph.D. in fundamental physics from Sussex University U.K. in 1985 and 1989 respectively. He joined the Optoelectronics Research Centre (ORC) at Southampton University as a Research Fellow in May 1989. He was awarded a Royal Society University Fellowship in 1991 in recognition of his pioneering work on short pulsed fiber lasers. Professor Richardson is now a Deputy Director of the ORC and is responsible for much of the ORC's fiber related activities. His current research interests include amongst others: optical fiber communications, microstructured fibers and high-power fiber lasers. Professor Richardson has published more than 600 conference and journal papers during his time at ORC and produced over 15 patents. He is a frequent invited speaker at the leading optics conferences and an active member of the international optics community. Professor Richardson is one of the co-founders of Southampton Photonics Incorporated a University spin-off venture which has successfully commercialised elements of high power laser technology developed within the ORC. He is a Fellow of the Optical Society of America and of the Institute of Engineering and Technology. 